\section{Primary Intraosseous Meningioma}

Kyoung Wook Choi, Kyu Jin Chung, Yong-Ha Kim

Department of Plastic and Reconstructive Surgery, Yeungnam University College of Medicine, Daegu, Korea

Correspondence: Yong-Ha Kim

Department of Plastic and Reconstructive Surgery, Yeungnam University College of Medicine, 170 Hyeonchung-ro, Nam-gu, Daegu 705-717, Korea Tel: +82-53-620-3480, Fax: +82-53-626-0705, E-mail: yhkim@med.yu.ac.kr

This article was presented as a poster at the 71th Congress of The Korean Society of Plastic and Reconstructive Surgeons on Nov 1-3, 2013 in Seoul, Korea.

This work was supported by the 2013 Yeungnam University Research Grant.

No potential conflict of interest relevant to this article was reported.

Received: 24 Jul 2014 • Revised: 5 Aug 2014 • Accepted: 23 Aug 2014 pISSN: 2234-6163 • elSSN: 2234-6171

http://dx.doi.org/10.5999/aps.2015.42.3.378 • Arch Plast Surg 2015;42:378-380

Copyright @ 2015 The Korean Society of Plastic and Reconstructive Surgeons

This is an Open Access article distributed under the terms of the Creative Common

Attribution Non-Commercial License (http://creativecommons.org/licenses/by-nc/3.0/) which permits unrestricted non-commercial use, distribution, and reproduction in any medium, provided the original work is properly cited.

Meningioma originates from arachnoid cap cells and is usually dura-based and slow growing. They account for $15 \%$ to $20 \%$ of primary brain tumors. Primary intraosseous meningioma (PIM) is a type of ectopic meningioma, and has been rarely reported. PIMs have been reported to constitute less than $2 \%$ of meningiomas, and are usual reported in the frontotemporal regions of the calvarium [1], orbits, and anterior cranial fossa. Frequently, patients with PIM of the orbit complain of aesthetic problems. We report a case of PIM of the orbit.

A 54-year-old female had presented with gradually progressive exophthalmos of 5 months duration (Fig. 1). The patient had no pain or visual symptom, and there was no previous ocular trauma history. Ophthalmologic and neurologic examinations were

Fig. 1.

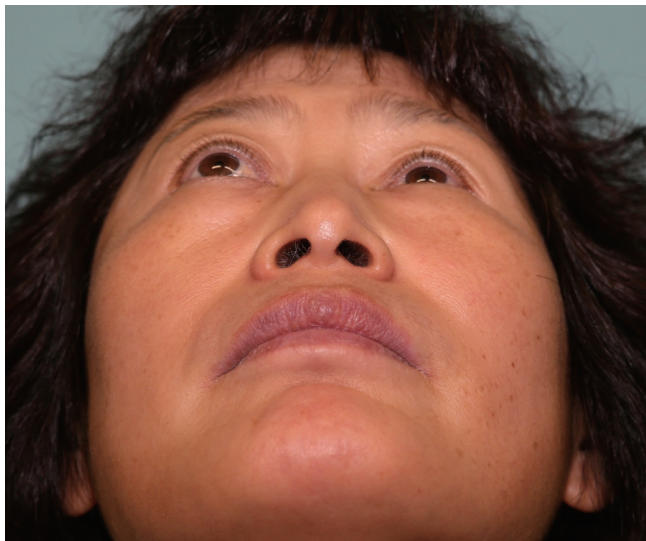

normal finding except for $5 \mathrm{~mm}$ of exophthalmos. Facial computed tomography (CT) scan revealed thickening of cortical bone of the orbital wall at the right sphenoid wing (Fig. 2). The radiologic diagnosis of preoperative facial CT was fibrous dysplasia of the right lateral orbital wall and right skull base.

Lateral eyebrow and subciliary incision were followed by parallel upper and lower ostectomies at the lateral orbital rim. The osteomised bone segment was excised to create enough space to approach the main mass at the right sphenoidal bone and part of the orbit lateral wall. The bony mass was removed with a high-speed drill and oscillating saw. The osteomised orbital rim segment was repositioned using fixation devices. The main mass consisted of fragile abnormal bone, resembling that of fibrous dysplasia.

Histopathologic examination confirmed the diagnosis of meningioma. In microscopic views, oval and spindle shaped cells formed lobules between woven bones. Nuclei frequently exhibited central clearing and whorls were viewed. Cytoplasm and surrounding collagen were immunohistochemically positive for epithelial membrane antigen, and negative for glial fibrillary acidic protein (GFAP), cytokeratin (AE1/AE3), and Ki-67 (Fig. 3). At 3 months after surgery, exophthalmos was reduced to 2 $\mathrm{mm}$, that is, into the relatively normal range (Fig. 4). On postoperative $\mathrm{CT}$, most of the bone mass was removed but minimal amount of mass remained (Fig. 5). Although secondary surgery for complete resection of the mass was planned at 12 months after surgery, the patient was satisfied with the aesthetic results and was not willing to undergo additional surgery.

Extradural meningiomas are uncommon, and more than $90 \%$ of extradural meningiomas occur in

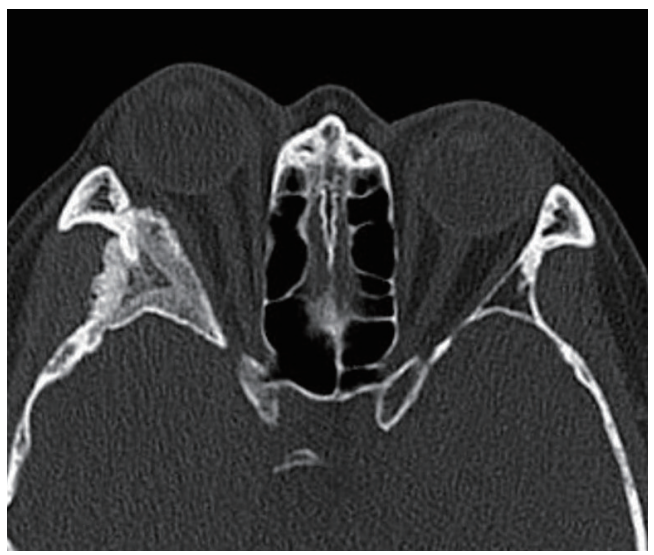

Fig. 2.

Preoperative facial computed tomography. 


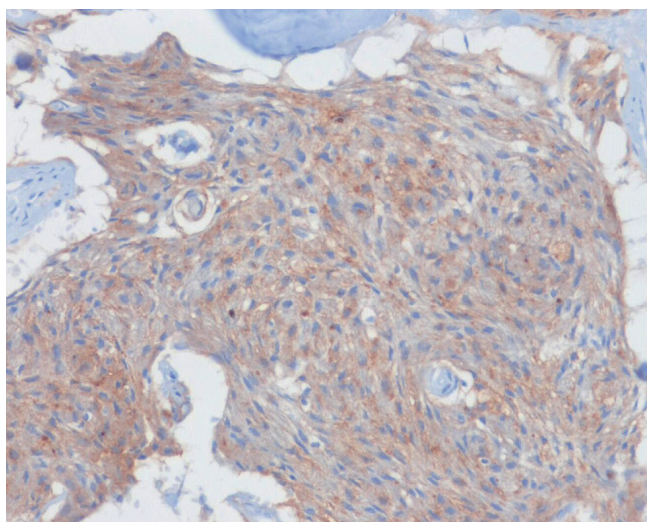

Fig. 3.

Epithelial membrane antigen positive finding (magnification, $\times 100$, epithelial membrane antigen immunostain).

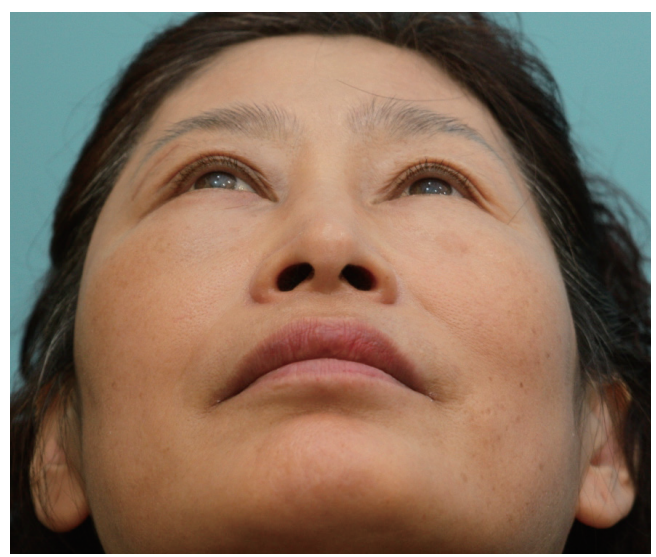

Fig. 4.

Postoperative view.

the head and neck [2]. Nevertheless, many other locations have been reported, such as, scalp, calvaria, orbit, paranasal sinus, neck, lung, mediastinum, skin, and finger. The differentiation of PIM and intradural meningioma depends on the presence of dural invasion. Hoye et al. [3] defined PIM as not involving the dura, but Lang et al. [2] did not treat dural invasion as an exclusive criteria and regarded main mass location, growth direction, and dural displacement pattern to be of greater importance.

The majority of PIMs of the skull base and orbital walls present with pain, exophthalmos, and deformity. PIMs are generally benign and slow growing, but a higher proportion are associated with malignant change than standard meningioma [2]. These tumors are characterized by an intraosseous mass growth leading to significant hyperostosis involving the sphenoid wing, orbital roof, lateral orbital wall, and the middle fossa cranial base and a thin, usually soft-

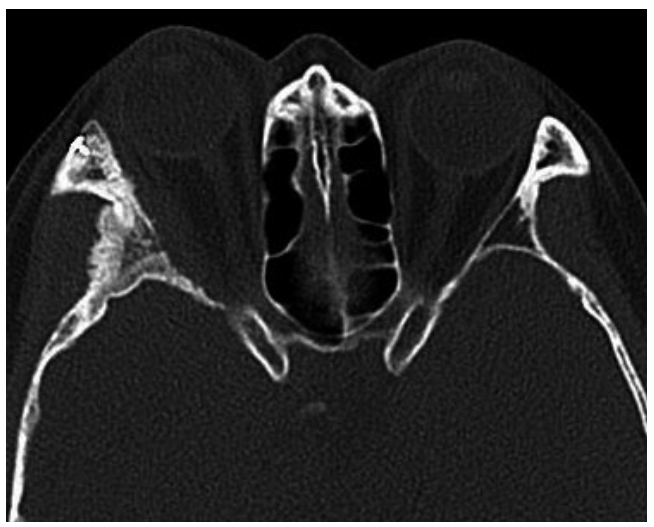

Fig. 5.

Postoperative facial computed tomography. tissue growth at the dura.

Several hypotheses have been proposed for the origin of PIM. Azar-Kia et al. [4] suggested that PIM arises from arachnoid cap cells trapped in the cranial suture during birth. In the reports issued by Lang et al. [2] and Crawford et al. [5] 8\% and 64\%, respectively, were suture related masses. It has also been proposed that PIM arises from dura and arachnoid entrapment caused by previous trauma. The third hypothesis is extradural meningioma arise from multipotent mesenchymal cells, which could explain masses located far from the head and neck.

PIM is the condition most commonly confused with fibrous dysplasia. Both PIM and fibrous dysplasia expand bone and have a "ground glass" appearance. However, in intraosseous meningioma, there is irregularity of the cortical bone. In fibrous dysplasia, on the other hand, the bone is enlarged but follows the normal position and intact cortical bone.

Surgical resection is required for symptomatic PIM. Excision of the tumor with reconstruction of bone as required is the choice of operation. Operations must be designed to achieve symmetry of both eyes, as proper facial symmetry and tumor resection are important for achieving successful aesthetic outcomes.

In conclusion, we reported a rare case of PIM of the orbit that present with progressive exophthalmos. Surgical resection was performed to lessen avoidable morbidity. The patient was satisfied with the aesthetic results achieved.

\section{References}

1. Adada B, Al-Mefty O. Fibrous dysplasia of the clivus. Neurosurgery 2003;52:318-22.

2. Lang FF, Macdonald OK, Fuller GN, et al. Primary extradural meningiomas: a report on nine cases and 
review of the literature from the era of computerized tomography scanning. J Neurosurg 2000;93:940-50.

3. Hoye SJ, Hoar CS Jr, Murray JE. Extracranial meningioma presenting as a tumor of the neck. Am J Surg 1960;100:486-9.

4. Azar-Kia B, Sarwar M, Marc JA, et al. Intraosseous meningioma. Neuroradiology 1974;6:246-53.

5. Crawford TS, Kleinschmidt-DeMasters BK, Lillehei KO. Primary intraosseous meningioma: case report. J Neurosurg 1995;83:912-5

\section{Benign Lymphoepithelial Lesion of Parotid Gland and Secondary Amyloidosis as Concurrent Manifestations in Sjögren's Syndrome}

Hii-Sun Jeong ${ }^{1}$, Hye-Kyung Lee ${ }^{2}$, You-Jung $\mathrm{Ha}^{3}$, Dae-Hyun Kim ${ }^{4}$, In-Suck Suh ${ }^{1}$

${ }^{1}$ Department of Plastic and Reconstructive Surgery, Hallym University Medical Center, Halllym University College of Medicine, Seoul; ${ }^{2}$ Department of Plastic and Reconstructive Surgery, Eulji General Hospital, Eulji University School of Medicine, Seoul; ${ }^{3}$ Department of Rheumatology, Yonsei University College of Medicine, Seoul; ${ }^{4}$ Department of Plastic and Reconstructive Surgery, Myong-Ji Hospital, Goyang, Korea

Correspondence: Hii-Sun Jeong

Department of Plastic and Reconstructive Surgery, Kangnam Sacred Heart Hospital, Hallym University Medical Center, Hallym University College of Medicine, 1 Singil-ro, Yeongdeungpo-gu, Seoul 150-950, Korea

Tel: +82-2-829-5182, Fax: +82-2-829-5183

E-mail: hiisunj@gmail.com

The authors thank Sung-Eun Kim, MD and Jae-Hyun Suk, MD, for kind assistance in clinical and pathological description of this article.

This article was presented as a poster at the 70th Congress of the Korean Society of Plastic and Reconstructive Surgeons on November 9, 2012 in Seoul, Korea.

No potential conflict of interest relevant to this article was reported.

Received: 30 Mar 2014 • Revised: 24 Jun 2014 • Accepted: 25 Jun 2014 pISSN: 2234-6163• elSSN: 2234-6171

http://dx.doi.org/10.5999/aps.2015.42.3.380 • Arch Plast Surg 2015;42:380-383

Copyright (C) 2015 The Korean Society of Plastic and Reconstructive Surgeons

This is an Open Access article distributed under the terms of the Creative Commons

Attribution Non-Commercial License (http://creativecommons.org/licenses/by-nc/3.0/) which permits unrestricted non-commercial use, distribution, and reproduction in any medium, provided the original work is properly cited.

Benign lymphoepithelial lesion (BLEL) is also known as lymphoepithelial sialadenitis, lymphoepithelial lesion, myoepithelial sialadenitis, and Sjögren's-type sialadenitis. It was first reported by Johann von Mikulicz-Radecki (1888) as synchronous inflammation of lacrimal and salivary glands [1].
Sjögren then referred to it as sicca syndrome, owing to salivary gland hyposecretion [1]. Goldwin first described the lymphoepithelial changes of BLEL in major salivary glands, presenting as unilateral or bilateral glandular enlargement without clinical signs of Sjögren's syndrome [1]. However, Morgan and Castleman were the first to detail the histopathologic hallmarks of BLEL, namely marked lymphoplasmacytic infiltration with residual epimyoepithelial islands (punctuated by hyperplastic and metaplastic ducts) and acinar degeneration [1].

In amyloidosis, insoluble polymeric protein fibrils are deposited in tissues and organs extracellularly. Secondary (AA) amyloidosis is characterized by accumulation of serum amyloid protein that is triggered in the setting of chronic inflammatory or infectious disease [2].

Reported here, with a review of the literature, is a patient with BLEL and secondary amyloidosis of the parotid gland as concurrent manifestations of Sjögren's syndrome.

A 51-year-old patient arrived at our facility with a left cheek mass ( $3 \mathrm{~cm}$ in diameter), which was firm, fixed, and non-tender, although eliciting related complaints of tightness and mild pain (Fig. 1). Upon assessment of facial features, mild, bilateral enlargement of lacrimal and submandibular glands

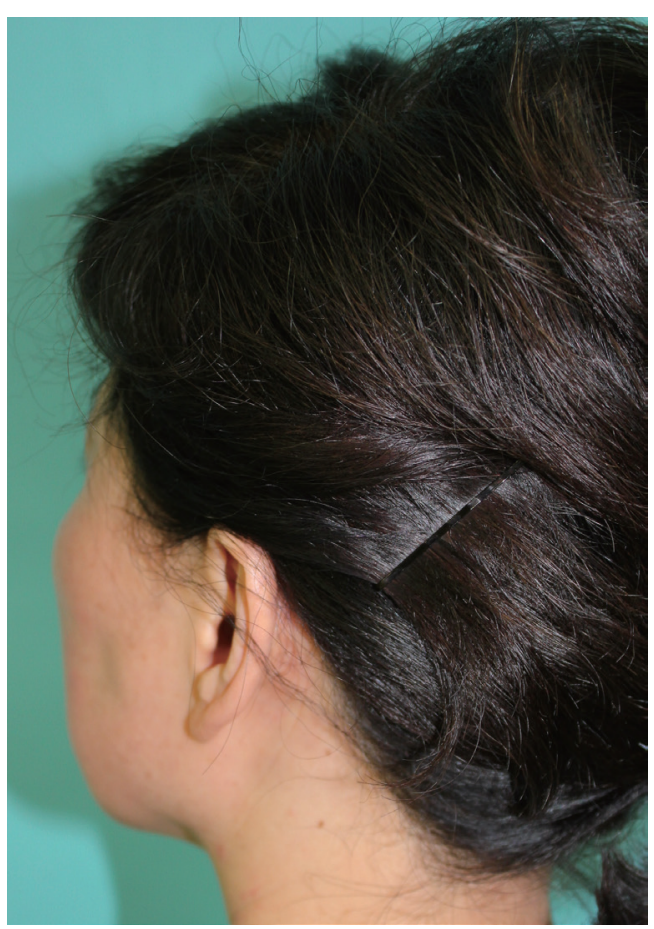

Fig. 1.

Initial appearance. 